Author Accepted Version. Final version published as: Temple, J. B., Kelaher, M., Brooke, L., Utomo, A., \& Williams, R. (2020). Discrimination and disability: Types of discrimination and association with trust, self-efficacy and life satisfaction among older Australians. Australasian journal on ageing, 39(2), 122-130.

\title{
Discrimination and Disability: \\ Types of Discrimination and Association with Trust, Self-Efficacy and Life Satisfaction among Older Australians
}

\begin{abstract}
(150 words)
Objective: To examine the prevalence, context and types of discrimination reported by older Australians (aged 55 years and over) and associations between outcomes (trust, self-efficacy and life satisfaction) and exposure to discrimination.

Methods: The 2014 General Social Survey was used to measure discrimination. Multivariable logistic regression was used to examine associations between levels of trust, self-efficacy and life satisfaction and exposure to discrimination.

Results: A sizeable minority of older Australians with a disability reported discrimination (15\%), with higher exposure for those with more severe or multiple disabilities. In addition to disability, age and nationality, race, or ethnic group were cited as reasons for discrimination. Discrimination was reported across a variety of contexts, including everyday social interactions. Lower levels of trust, self-efficacy and life satisfaction were associated with exposure to disability discrimination. Conclusion: Focusing on disability discrimination alone underestimates the level of exposure to discrimination. Discrimination may reinforce social exclusion by reducing trust and self-efficacy in familial and community contexts.
\end{abstract}

Keywords: Ageing, Disability, Discrimination, Intersectionality. 


\section{Impact Statement (50 words)}

Our study highlights the damaging impacts of discrimination on older Australians living with a disability. Policy may counter damaging effects through programs to enhance social inclusion. The existing legal framework to protect people with disabilities from discrimination requires review in light of the levels and consequences of discrimination we uncover. 


\section{Discrimination and Disability: \\ Types of Discrimination and Association with Trust, Self-Efficacy and Life Satisfaction among older Australians}

\section{Introduction}

A review of articles from the $A J A$ from 1982 to 2016 highlighted research on ageism, across domains of community and health professional attitudes towards ageing, age discrimination and work, and policy [1]. The sustained interest in issues around ageism over the last 30 years is not surprising given the considerable evidence base on the health consequences of exposure to ageism including poorer mental health [2], poorer assessed wellbeing [3], and worse self-rated health, functional limitations and chronic illness [4].

Less research attention, however, has been directed towards broader conceptualisations of discrimination in later life and how it is experienced by different population groups. While age discrimination itself can intensify the social exclusion of older people in Australia [5], other forms of discrimination that are not necessarily age-related may compound social disadvantage in later life. For example, recent studies have underscored the considerable exposure to racial discrimination by older Aboriginal and Torres Strait Islander people [6]. Others have cited the deleterious consequences of discrimination due to sexuality for older LGBT Australians [7].

One group of Australians that have been cited as particularly prone to discrimination and at risk of social exclusion are people living with disabilities [8-11]. To date, there is scant population-level evidence on the types of discrimination reported by older people living with disabilities. For some people with a disability, discrimination may be associated with experiencing barriers to healthcare at different points in the healthcare system [12]. Other evidence suggests exposure to disability 
discrimination is significantly associated with poor mental health outcomes in later life [13]. However, little is known about the types of discrimination reported by older people with disabilities that are not directly attributable to their disability or health condition alone. Moreover, there is little empirical work on associations between consequences, such as facilitators of social inclusion and general measures of wellbeing, and exposure to discrimination.

This study utilises a sample of Australians aged 55 and over living with disabilities drawn from nationally representative data from the 2014 General Social Survey (GSS). Although the younger respondents in this population may be considered late middle-aged people, in this paper we adopt the term "older people" to refer to all persons over 55. We sought to answer three questions regarding the experiences of interpersonal discrimination reported by older Australians living with disabilities. First, what is the prevalence of older Australians reporting any form of discrimination and how does it differ by measures of disability? Second, does the type (e.g., racism) or context (e.g., healthcare) of discrimination differ by disability status? Finally, among older people with disabilities, is exposure to discrimination associated with facilitators of social inclusion (including trust in institutions and people, self-efficacy) and overall life satisfaction?

\section{Methods}

Data

Data for this study were from the 2014 General Social Survey (GSS) conducted by the Australian Bureau of Statistics (ABS) between March and June 2014 [14]. Using a face-to-face interview

along with prompt cards, the ABS collected information using a Computer Assisted Interviewing (CAI) questionnaire on a range of domains to understand the "multi-dimensional nature of relative 
advantage and disadvantage across the population, and to facilitate reporting on and monitoring of people's opportunities to participate fully in society" [15].

The GSS included an initial sample of 18,574 private dwellings of which 16,145 dwellings were used due to issues of scope or uninhabited dwellings. In total, $80 \%$ fully responded, yielding a sample of 12,932 people aged 15 years and over. From this final sample, only respondents aged 55 years and over were included, yielding a final sample size of 4,967 respondents.

Data for the GSS were collected by the ABS under the provisions of the Census and Statistics Act (CSA) 1905. Confidentialised data and access to the Remote Access Data Laboratory (RADL) were made available to the authors for this study through the ABS and Universities Australia agreement. Ethics approval for this project was granted by the Melbourne School of Population and Global Health Human Ethics Advisory Group (HEAG) - Ethics ID: 1953686.1.

\section{Measures}

\section{$\underline{\text { Discrimination }}$}

The 2014 GSS included a module (Module 8.16) examining the experiences of discrimination in Australia. Respondents were asked, "In the past 12 months, that is since this time last year, do you feel that you have experienced discrimination or have been treated unfairly by others?" Those who responded positively were further prompted: "In the past 12 months, in which places or situations do you feel that you have experienced discrimination or have been treated unfairly?" A prompt card was then shown (Prompt card F25) with a list including: "at home, at work, at the shop, on public transport, at school or university, in a restaurant or bar, on the street or in a public place, online, applying for work/jobs, applying for or keeping a flat/apartment or housing of any kind, 
dealing with police, dealing with the courts, dealing with government officials, dealing with people involved in health care, other or don't know".

Respondents were further asked "Thinking about your most recent experience of discrimination in Australia, do you think it was because of any of the following?" A prompt card was then displayed (Prompt Card F27) listing: "your skin colour, your nationality, race or ethnic group, the language you speak, the way you dress or your appearance, your gender, your age, a disability or health issue, your marital status, your family status, your sexual orientation, your occupation, your religious beliefs, your political position or other".

\section{Disability}

The ABS measure of disability is any limitation, restriction or impairment which restricts everyday activities and has lasted, or is likely to last, for at least six months. Disability in the GSS is operationalised using the ABS short disability module (SDM) which includes 10 questions to gauge levels of disability. With the exception of the Survey of Disability and Carers (SDAC), most ABS sample surveys measuring disability adopt the SDM. Despite its widespread use, this measure has limitations, discussed below.

\section{Trust, Self-Efficacy and Life Satisfaction}

The GSS included separate modules on trust, self-efficacy and life satisfaction. For the module on trust (module 8.15), respondents were asked "How strongly do you agree or disagree with the following statements: That most people can be trusted?” A prompt card was shown (Prompt card F24) displaying: "1. Strongly agree, 2. Somewhat agree, 3. Neither agree nor disagree, 4. 
Somewhat disagree or 5. Strongly disagree". This question was repeated for trust in the healthcare system, police and justice system.

Measures of self-efficacy were included in the network advice and opinions module (Module 8.14). Respondents were asked "How often do you feel you are able to have a say with your family or friends, on issues that are important to you?" A prompt card was displayed listing: "1. All of the time, 2. Most of the time, 3. Some of the time, 4. A little of the time, 5. None of the time". This question was replicated for self-efficacy within 'the general community'. These measures are operationalised by the Australian Bureau of Statistics as broad indicators of self-efficacy [14]. We note that this simple measure is unlikely to capture the multidimensional nature of self-efficacy in practice, but nonetheless serves as a useful proxy.

As a summary measure of overall life satisfaction, respondents were prompted: "The following question asks how satisfied you feel, on a scale from 0 to 10 . Zero means you feel "not at all satisfied" and 10 means "completely satisfied". Overall, how satisfied are you with your life as a whole these days?".

\section{Statistical Tests}

Tests of proportions were used to examine differences in the prevalence of discrimination by disability characteristics (eg., disability type). Tests of proportions were also used to compare and contrast the attribution of discrimination (eg., skin colour, gender) and the contexts in which it occurs (eg., at home, the workplace) between respondents with and without disabilities. Ordinal logistic regression models were used to examine the association between exposure to 
discrimination and trust, self-efficacy and overall life satisfaction. Using the raw logit coefficients, we calculated odds ratios (OR) which measure the change in the odds of reporting poor trust, poor self-efficacy or life satisfaction given exposure to discrimination, once all other factors in the model were controlled for.

Due to the complex survey design, adjustments were necessary to generate correct variance estimates. The GSS includes 60 replicate weights on the data file to adjust for sample design and non-response. We employed the unstratified delete-one jackknife method to make the necessary replicate adjustments. Although many covariates may be associated with trust, self-efficacy and life satisfaction, we present relatively parsimonious models with controls for age, sex, country of birth and self-rated health. The need to estimate parsimonious models is pronounced due to the relative rarity of measures of discrimination combined with the need to employ the jackknife procedure outlined above. With too many covariates included, matrix conformability problems can occur. Nonetheless, our model specification is robust to multicollinearity and is confirmed by standard model selection techniques. As will be shown, our multivariable results are highly consistent with the underlying bivariate relationships.

\section{Results}

Table 1 displays prevalence rates of reported discrimination disaggregated by measures of disability. Just under $15 \%$ of older Australians with a disability reported discrimination, compared with $9 \%$ of those without a disability. Those living with a profound/severe $(18 \%)$ or moderate/mild (12\%) disability were more likely to report discrimination than those with no disability or longterm health conditions. As a further proxy of the severity of disability, the more disabilities the 
person had, the higher the likelihood of reporting discrimination. Reports of discrimination were also heightened for those living with specific types of disabilities including intellectual (23\%), psychological (28\%) and head injury, stroke or brain damage (27\%).

These aggregate level results show clear differences in reports of discrimination by various measures of disability. A further important query is how reports of discrimination differ by the type (Table 2) and context (Table 3) of discrimination.

Table 2 displays the differences in attributed reasons for discrimination by disability status and exposure to disability and health discrimination. Of the $15 \%$ of people with a disability reporting an instance of discrimination, one-in-five reported their disability or health condition as the reason for the discrimination (20\%). Approximately one third of those with a disability cited age as the reason for discrimination (32\%). The tests of proportions indicated no significance difference in exposure to age discrimination between respondents with and without a disability. Moreover, exposure to age discrimination did not vary with the likelihood of reporting disability and health discrimination. About $20 \%$ of respondents with a disability cited 'nationality, race or ethnic group' or other as the reason for discrimination. Relative to those without a disability, those with a disability were more likely to cite 'the way you dress or appearance'. Around $12 \%$ of respondents, regardless of disability status, cited gender as the reason for discrimination.

Table 3 displays the distribution of the context of discrimination by disability status and presence of disability and health discrimination. The key finding from this table is that respondents reported considerable heterogeneity in the contexts of discrimination, regardless of disability status. For 
those with a disability, contexts of discrimination reported by more than one in five exposed to discrimination, included the workplace (33\%), on the street or in a public place $(22 \%)$, at the shops (21\%), dealing with government officials (19\%) and people involved in healthcare (18\%). Relative to those without a disability, those with a disability were less likely to cite workplace discrimination and more likely to cite exposure from people working in healthcare and other sources.

Our final research objective was to investigate the association between discrimination exposure with respondents' levels of trust in institutions, self-efficacy and overall life satisfaction. In Table 4, we present unadjusted Odds Ratios (OR) and adjusted odds ratios (with control variables included) measuring the significance and strength of the association between exposure to discrimination and (1) trust in institutions including healthcare, justice, police and people; (2) selfefficacy within close family and friend networks and the general community, and (3) overall life satisfaction. These models refer to the population of older Australians living with a disability only.

In both unadjusted and adjusted models, exposure to any type of discrimination approximately doubled the odds of reporting low levels of trust in healthcare $(\mathrm{OR}=1.9 \mathrm{p}<0.001)$, justice $(\mathrm{OR}=$ $2.1 \mathrm{p}<0.001)$, police $(\mathrm{OR}=2.2 \mathrm{p}<0.001)$ and people $(\mathrm{OR}=2.0 \mathrm{p}<0.001)$. When disaggregated by whether the form of discrimination was disability or health related or not, the parameter coefficients remain strongly significant between the two groups, with the strength of the coefficients slightly higher for the former group. 
Similarly, exposure to discrimination was found to be associated with lower levels of self-efficacy $(\mathrm{OR}=1.6 \mathrm{p}<0.001)$ particularly as it occurred within familial and friendship groups. Again, the coefficients for disability and health discrimination $(\mathrm{OR}=1.9 \mathrm{p}<0.05)$ were higher than those for non-disability discrimination ( $\mathrm{OR}=1.5, \mathrm{p}<0.01)$. Interestingly, only disability discrimination was associated with poor levels of self-efficacy within the general community $(\mathrm{OR}=2.46, \mathrm{p}<0.001)$, with no significant associations for non-disability discrimination $(\mathrm{p}>0.1)$.

Reporting disability discrimination reduced the odds of achieving a one-point higher score on selfrated life satisfaction by $55 \%(\mathrm{OR}=0.45 \mathrm{p}<0.05)$. Other forms of discrimination were associated with a $39 \%$ reduction in self-rated life satisfaction scale $(\mathrm{OR}=0.61 \mathrm{p}<0.01)$. These model results are robust to complex survey design and include comprehensive controls for age, sex, country of birth and self-assessed health.

\section{Discussion}

A sizeable minority of older Australians with a disability report discrimination (15\%), with exposure higher for those with more severe or higher numbers of disabilities, and for those with specific intellectual, psychological and head injury, stroke or brain-damage-related disabilities. In contrast, a lower percentage of older Australians who reported no disability reported experiencing discrimination (9\%). The finding that people with disabilities, and in particular more severe disabilities, are at a higher risk of experiencing any type of discrimination (relative to those without disabilities) is not surprising and is consistent with a large evidence base on disability stigma [1617], and growing evidence base on disability discrimination specifically [9-13]. 
Our results suggest that focusing on disability discrimination alone biases the total level of discrimination reported by people with disabilities. Among older Australians living with disability, our GSS-based estimate of reported any type of discrimination is higher (15\%) than the estimated prevalence of disability-related discrimination based on the ABS Survey of Disability and Carers (SDAC) (4.5\%) [11]. Of the $15 \%$ in this study noting discrimination, only one-in-five noted it was due to their health condition or disability. The small difference in disability discrimination between SDAC and the GSS is likely to be attributable to the measurement of disability (discussed below).

Respondents with disabilities were not more likely to cite age as the reason for discrimination than those without. This is expected, as it is conceptually difficult to separate disability/health-related discrimination and age-based discrimination given the complex interactions between ageing, and the onset or progression of disability [18]. For example, Mastin and Priestley [19] argue that the strong associations between biological ageing and the onset of disability operate through cultural and structural pathways, as well as through social movements.

Apart from age, issues around language, and nationality, race or ethnic group also featured strongly as reasons for discrimination. In addition to language barriers, geographical location and circumstances of migration [20], experiencing racial discrimination may result in individuals having restricted access to resources required for health, adequate housing, education, employment and service provision [21]. The consequences of poor economic security, social exclusion and discrimination result in poor psycho-social health [22]. 
Older Australians with a disability also reported discrimination across a variety of contexts in their everyday social interactions. Compared to those without a disability, those with a disability were less likely to report workplace discrimination and more likely to report exposure from people working in healthcare and other sources. This is expected given lower levels of employment among older adults living with a disability. Experiencing discrimination in everyday social interactions is important as it has been linked to 'label avoidance' - the active avoidance of contexts around service use (eg., social services, medical treatment, education and workplaces) as a direct result of a fear of public consequences of being labelled [16]. It also underscores significant levels of disability stigma in Australia generally [8]. Experiencing discrimination in contexts important to healthcare is important because of the association with reporting a barrier to healthcare and subsequent non-adherence to treatment regimens $[12,23,24]$. Discrimination in workforce contexts is important because barriers to workplace engagement can reduce economic security and thereby reduce financial resources that may otherwise be directed toward protecting health $[25$, 26].

We further found that facilitators of social inclusions, such as trust in institutions and community and self-efficacy in familial and community contexts, was negatively associated with exposure to discrimination. Indeed, the Australian government recognises that discrimination is antithetical to promoting social inclusion. The former head of the Australian Human Rights commission has previously acknowledged that "We know that there is a correlation between discrimination and social exclusion...The existence of a strong civil society is fundamental for an inclusive society and active participation in Australian life...Strong community engagement provides opportunity, builds wealth, promotes social harmony, and ensures greater equality and justice for all citizens" [27]. 
Our finding that discrimination is associated with low trust is consistent with other studies [28]. The relationship is important, as living in a high-trust community may improve health and thus indirectly enhance subjective wellbeing [29]. Furthermore, a recent longitudinal Australian study found that among older people, low generalised trust was associated with transitioning into poor physical functioning, poor mental health and poor self-rated health [30]. More generally, lower levels of trust in healthcare may indicate a higher likelihood of experiencing a barrier to healthcare in Australia [31]. Low trust in law and police is problematic given that people with disabilities are at a higher risk of physical violence, sexual harassment, and stalking [32].

Given discrimination was associated with poor levels of trust, it was not unexpected that exposure was also associated with low levels of self-efficacy, particularly within familial and friendship groups. This result is consistent with the World Health Organization's view that discrimination leads not only to lower levels of self-efficacy but also to decreased productivity and poorer health [33]. Stereotypes can become self-fulfilling prophesies: when internalised, they may paralyse the person into inaction and thus exacerbate deficits in social participation [34].

Finally, we observed that discrimination was associated with lower levels of self-assessed life satisfaction, even with controls for demographic and health characteristics and controls for complex survey design. This result is consistent with a recent analysis of the European Social Survey, spanning six waves (2002-2012), which found exposure to discrimination reduced life satisfaction. Importantly, these authors also noted a significant relationship between discrimination, life satisfaction and social inequality, with 'a drop as large as would accompany 
moving more than half-way down the income distribution' [28; p. 14]. Goff, Helliwell, and Mayraz (2018), further confirmed this finding based on analyses of large-scale international surveys (the European Social Survey, the World Values Survey, the Gallup World Poll, and the GallupHealthways Well-Being Index (survey waves 1995-2015))[35].

\section{Limitations}

Interpretation of our findings needs to be balanced by the limitations of the data and analysis. One important limitation of this study is the measurement of disability. The ABS Survey of Disability and Carers (SDAC) uses the gold standard measurement of disabilities used across Government in Australia. This module includes over one hundred questions to gauge the presence and type of disability. The GSS and all other ABS CURFS (including the National Health Survey) provide an overestimate of disability relative to the SDAC. The SDAC estimates that $21 \%$ of the population aged 18 years and over living in private household has a disability. The comparable figure for the GSS is $32 \%$ (11 percentage points difference). Restricting the population to those aged 55 years and over, approximately $39 \%$ of those living in households, live with a disability, relative to $51.5 \%$ of those in the GSS (12.5 percentage point difference). The ABS note that an

"implication for data users is that surveys using the Short Disability Module will probably show disability population characteristics that are somewhat more like the general population than the disability population as described in SDAC .... Thus, if disability is related to a characteristic, the broader disability group identified by the Short Disability Module will display a weaker relationship to that characteristic." [36].

Another limitation of this study is that the GSS data are cross-sectional. We cannot draw causal inferences about exposure to discrimination and trust, self-efficacy and life satisfaction. 
Unfortunately, there is a dearth of nationally representative longitudinal data with measures of discrimination and disabilities in Australia, in which this association could be explored further.

Finally, our analysis relies on self-reported response to a series of questions on interpersonal discrimination in the GSS. Structural discrimination is an important component of the exclusion faced by people living with disabilities and is not captured in this study.

\section{Conclusion}

Despite the above limitations, our results are the first nationally representative analyses of the types of discrimination reported by older Australians with disabilities. A sizeable minority of older people and those in late middle-age reported discrimination (15\%) with only one-in-five of this group attributing discrimination to their disability or health conditions. In addition to disability or health conditions, discrimination was also attributed to age and issues around language, and nationality, race and ethnic group. Using self-reported data from the GSS, we found discrimination occurs in a variety of contexts, and demonstrated that perceived exposure to a range of interpersonal discrimination may reinforce social exclusion of people with disabilities through its negative association with both the levels of trust in institutions and communities and with selfefficacy particularly in familial and community contexts.

Our findings indicate the need for further analysis on how discrimination is experienced in later life - including the different types of discrimination and consequences of this exposure between population sub-groups. Discrimination tends to be understudied in older people because exposure to many forms of discrimination (eg., racism) decreases over the lifecourse [37]. Ageism is a 
notable exception, and this clearly intersects with the increase in disability as people age [37]. Failing to address intersectionality between ageing and disability may (1) underrepresent the prevalence of discrimination experienced by people living with disabilities, and (2) produce tensions and be counterproductive to current policy narratives around healthy/successful ageing and social inclusion $[38,39]$. Considering the intersection between ageing and disability is critical

to developing a person-centred response to addressing discrimination and improving care and inclusion.

\section{References}

1. Malta S, Doyle C. Butler's three constructs of ageism in Australasian Journal on Ageing. Australasian Journal on Ageing 2016; 35:232-235.

2. Lyons A, Alba B, Heywood W, Fileborn B, Minichiello V, Barrett C, Hinchliff S, Malta S, Dow B. Experiences of ageism and the mental health of older adults. Aging \& Mental Health 2018; 22:1456-1464.

3. Garstka, TA, Schmitt MT, Branscombe NR, Hummert ML. How young and older adults differ in their responses to perceived age discrimination. Psychology and Aging 2004;19:326-335.

4. Luo Y, Xu J, Granberg E, Wentworth WM. A longitudinal study of social status, perceived discrimination, and physical and emotional health among older adults. Research on Aging 2012; 34:275-301.

5. Lui C.-W, Warburton J, Winterton R, Bartlett H. Critical Reflections on a Social Inclusion Approach for an Ageing Australia. Australian Social Work 2011;64:266-282. 
6. Temple JB, Kelaher M, Paradies Y. Prevalence and context of racism experienced by older Aboriginal and Torres Strait Islanders. Australasian Journal on Ageing 2019;38:3946.

7. Tinney J, Dow B, Maude P, Purchase R, Whyte C, Barrett C. Mental health issues and discrimination among older LGBTI people. International Psychogeriatrics 2015;27:1411-1416.

8. Australian Government. Shut Out: The experience of people with disabilities and their families in Australia. National Disability Strategy Consultation Report prepared by the National People with Disabilities and Carer Council. 2009. https://www.dss.gov.au/sites/default/files/documents/05_2012/nds_report.pdf. Accessed March 25, 2019.

9. Krnjacki L, Priest N, Aitken Z, Emerson E, Llewellyn G, King T, Kavanagh A. Disabilitybased discrimination and health: findings from an Australian-based population study. Australian and New Zealand Journal of Public Health 2018;42:172-174.

10. Temple JB, Kelaher M, Williams R. Discrimination and avoidance due to disability in Australia: Evidence from a national cross sectional survey. BMC Public Health 2018;18:1347.

11. Temple JB, Kelaher M, Utomo AJ, Williams R, Brooke L. Components of disability exclusion: Discrimination, avoidance and accessibility in later life. Australasian Journal on Ageing 2019; under review.

12. Temple JB, Stiles J, Kelaher M, Utomo AJ, Williams R. Is disability exclusion associated with experiencing unmet needs for healthcare Australasian Journal on Ageing 2019; under review; 
13. Temple, JB, Kelaher, M., \& Williams, R. Disability discrimination and avoidance in later life: prevalence, disability differentials and association with mental health. International Psychogeriatrics 2018; n.d.: 1-11. https://doi.org/10.1017/S1041610218001722.

14. ABS. Microdata: General Social Survey, Australia, 2014. ABS Cat. No. 4159.0.30.004. Canberra: Australian Bureau of Statistics. 2015

15. ABS. General Social Survey: Summary Results, Australia, 2014. Catalogue Number 4159.0. Canberra: Australian Bureau of Statistics; 2015.

16. Corrigan $\mathrm{P}$, ed. The stigma of disease and disability: understanding causes and overcoming injustices. Washington, DC: American Psychological Association; 2013.

17. Brown R. Understanding the influence of stigma and discrimination for the functional limitation severity - psychological distress relationship: A stress and coping perspective. Social Science Research 2017; 62:150-160.

18. Gale CR, Cooper C, Sayer AA. Prevalence of frailty and disability: findings from the English Longitudinal Study of Ageing. Age and Ageing 2014;44:162-165.

19. Mastin G \& Priestley, M. Disability and age discrimination In M. Sargeant (Ed.), Age discrimination and diversity: Multiple discrimination from an age perspective. Cambridge: Cambridge University Press; 2011.

20. Rao DV, Warburton J, Bartlett H. Health and social needs of older Australians from culturally and linguistically diverse backgrounds: issues and implications. Australasian Journal on Ageing 2006; 25:174-179.

21. Warburton J, Bartlett H, Rao V. Ageing and Cultural Diversity: Policy and Practice Issues, Australian Social Work 2009;62:168-185, 
22. Ferdinand A, Paradies Y, Kelaher M. Mental health impacts of racial discrimination in Australian culturally and linguistically diverse communities: A cross-sectional survey, BMC Public Health 2015;15:401.

23. Moscoso-Porras M, Alvarado G. Association between perceived discrimination and healthcare-seeking behaviour in people with a disability. Disability Health Journal 2018;11:93-98.

24. Van Houtven C, Voils C, Oddone E, Weinfurt K, Friedman J, Schulman K, Bosworth H. Perceived discrimination and reported delay of pharmacy prescriptions and medical tests. Journal of General Internal Medicine 2005;20:578-583.

25. Ranzijn R, Carson E, Winefield A and Price D. On the scrap-heap at 45: the human impact of mature aged unemployment. Journal of Occupational \& Organizational Psychology 2006;79:467-79.

26. Australian Human Rights Commission. Willing to Work, National inquiry into employment discrimination against older Australians and Australians with a disability. Australian Human Rights Commission;2016.

27. Triggs, G. Social Inclusion and Human Rights in Australia, Address at the Chain Reaction Foundation Breakfast Café, August 2013. Available at https://www.humanrights.gov.au/news/speeches/social-inclusion-and-human-rightsaustralia. Accessed March 25, 2019.

28. Helliwell JF, Huang H, Wang S. New Evidence On Trust And Well-Being. Working Paper 22450 National Bureau of Economic Research; 2016. http://www.nber.org/papers/w22450 
29. Helliwell JF, Putnam RD. The social context of well-being. Philosophical Transactions of the Royal Society of London. Series B: Biological Sciences 2004; 359:1435-1446.

30. Yiengprugsawan V, Welsh J, Kendig H. Social capital dynamics and health in mid to later life: Findings from Australia. Quality of Life Research 2018 May 1:1-6

31. Temple JB, Williams R. Multiple health conditions and barriers to healthcare among older Australians: prevalence, reasons and types of barriers. Australian Journal of Primary Health 2018; 24:82-89.

32. ABS. Experiences of Violence and Personal Safety of People with Disability, 2016. ABS Cat. No. 4431.0.55.003. Canberra: Australian Bureau of Statistics; 2018.

33. World Health Organization. World Report on Ageing and Health. World Health Organization; 2015.

34. Pugh R. Attitudes, stereotypes and anti-discriminatory education: Developing themes from Sullivan. The British Journal of Social Work 1998;28:939-959.

35. Goff L., Helliwell JF, Mayraz, G. Inequality of subjective well-being as a comprehensive measure of inequality. Economic Inquiry 2018; 56:2177-2194.

36. ABS. ABS Sources of Disability Information, 2012-2016. ABS Cat. No. 4431.0.55.002. Canberra: Australian Bureau of Statistics; 2018.

37. Gee GC, Hing A, Mohammed S, Tabor DC, Williams D. Racism and the life course: Taking time seriously. American Journal of Public Health 2019;109: s43.

38. McGrath C, Laliberte Rudman D, Polgar J , Spafford MM, Trentham B. Negotiating 'positive' aging in the presence of age-related vision loss (ARVL): The shaping and perpetuation of disability. Journal of Aging Studies 2016;39: 1-10. 
39. Romo RD, Wallhagen MI, Yourman L, Yeung CC, Eng C, Micco G, Pérez-Stable EJ, Smith AK. Perceptions of successful aging among diverse elders with late-life disability. The Gerontologist 2013;53:939-949. 


\section{University Library}

\section{- M M N E R VA A gateway to Melbourne's research publications}

Minerva Access is the Institutional Repository of The University of Melbourne

\section{Author/s:}

Temple, JB;Kelaher, M;Brooke, L;Utomo, A;Williams, R

Title:

Discrimination and disability: Types of discrimination and association with trust, self-efficacy and life satisfaction among older Australians

\section{Date:}

2019-11-21

\section{Citation:}

Temple, J. B., Kelaher, M., Brooke, L., Utomo, A. \& Williams, R. (2019). Discrimination and disability: Types of discrimination and association with trust, self-efficacy and life satisfaction among older Australians. AUSTRALASIAN JOURNAL ON AGEING, 39 (2), pp.122-130. https://doi.org/10.1111/ajag. 12747.

Persistent Link:

http://hdl.handle.net/11343/253846 